\title{
Effects of Rapid Thermal Annealing on the Properties of Room-Temperature Oxygenated DC Sputtered Zinc Thin Films for CZTS Solar Cells Application
}

\author{
Emmanuel R Ollotu $^{1^{*}}$, Nuru R Mlyuka ${ }^{2}$ and Margaret E Samiji ${ }^{2}$ \\ ${ }^{1}$ Physics Department, Mkwawa University College of Education, P. O. Box 2513, Iringa, Tanzania \\ ${ }^{2}$ Physics Department, University of Dar es Salaam, P.O. Box 35063 Dar es Salaam, Tanzania \\ *Corresponding author e-mails: manyoolo@gmail.com, erollotu@muce.ac.tz \\ Co-authors e-mails:nmlyuka@yahoo.com,esamiji@gmail.com
}

Received 14 Jan 2021, Revised 27 Apr 2021, Accepted 28 Apr 2021, Published May 2021

DOI: https://dx.doi.org/10.4314/tjs.v47i2.19

\begin{abstract}
This work investigated the potential to achieve zinc oxide $(\mathrm{ZnO})$ films for $\mathrm{Cu}_{2} \mathrm{ZnSnS}_{4}$ (CZTS) solar cells window layer at controlled annealing conditions as a potential approach to address elemental inter-diffusion in CZTS solar cells. This involved rapid thermal annealing (RTA) of room-temperature oxygenated DC sputtered zinc thin films in an ambient of nitrogen gas at different temperatures. Structural, morphological, optical, and electrical properties of these films were determined by X-ray diffractometer, Scanning Electron Microscopy, Ultraviolet-visible-near infrared spectrophotometer, and Hall Effect measurement, respectively. ZnO phases were observed after annealing the films over $150{ }^{\circ} \mathrm{C}$. The films' grains sizes improved with increasing RTA temperature. An exponential decrease in these films' resistivity was observed with increasing RTA temperature attaining the lowest value at $300{ }^{\circ} \mathrm{C}$. The bandgap and average solar transmittance of the films increased with increasing RTA temperature achieving values that are potential for applications in CZTS solar cells window layer at RTA temperatures beyond $200{ }^{\circ} \mathrm{C}$.
\end{abstract}

Keywords: Sputtering; Rapid thermal annealing; Zinc oxide; Structural; Opt-electrical.

\section{Introduction}

Zinc oxide $(\mathrm{ZnO})$ thin films have been broadly researched due to their potential properties applicable in different fields. These properties include the wide tunable bandgap (3.0-3.4 eV) and high exciton binding energy $(60 \mathrm{meV})$. Other properties include low-cost, non-toxicity, and thermal and chemical stability (Pholds et al. 2017). Therefore, $\mathrm{ZnO}$ has been researched for sensors, acoustic waves devices and optoelectronic devices such as light-emitting diodes and solar cells (Ozgur et al. 2010, Samwel et al. 2015). These films have been achieved using several methods including chemical vapour deposition, pulsed laser deposition, spray pyrolysis, molecular beam epitaxy, spin coating, thermal evaporation and sputtering. Among these methods, sputtering which is also reported to be versatile in the $\mathrm{ZnO}$ thin films production, achieve high-quality uniform films with exceptional physical and structural properties (Zhang et al. 2009).

$\mathrm{ZnO}$ thin films are usually sputtered at elevated substrate temperature to reduce structural defects, improve grains growth, and achieve crystalline films (Jang et al. 2010). However, these films have also been produced at low-temperature followed by controlled post-deposition heat treatment including rapid thermal annealing (RTA). Such an annealing approach is reported to be essential in achieving defects-rich $\mathrm{ZnO}$ films for specific applications (Hsieh et al. 2006). The low- 
temperature deposition has also been used in $\mathrm{ZnO}$ thin films to avoid cracking of the films due to high thermal expansion between substrate and films interface (Barker et al. 1997) and/or avoid adverse effects of underlayers or substrates (Ryu et al. 2017). In $\mathrm{Cu}_{2} \mathrm{ZnSnS}_{4}$ (CZTS) solar cells processing, the $\mathrm{ZnO}$ window layer is normally deposited on a $\mathrm{CdS}$ buffer layer at suitable temperatures to achieve a good quality window layer (Husna et al. 2012). These deposition temperatures can also be considered as an annealing process on the CdS under-layer usually deposited at relative lower room temperatures. Such temperatures have been reported to cause cadmium (Cd) inter-diffusion into CZTS and $\mathrm{Zn}$ and $\mathrm{S}$ into CdS affecting CdS/CZTS band alignment which disrupt carrier transport at this interface eventually affecting the CZTS solar cells performance (Pal et al. 2019). A potential approach to address this reported issue is to achieve $\mathrm{ZnO}$ thin films on $\mathrm{CdS}$ at controlled annealing environment. In this work, we assessed the potential to achieve $\mathrm{ZnO}$ thin films by RTA of room-temperature oxygenated DC sputtered $\mathrm{Zn}$ thin films in an ambient of nitrogen gas at different temperatures; an approach which is considered to be potential to address the aforementioned adverse effect in CZTS solar cells related to deposition temperature. $\mathrm{ZnO}$ films achieved by $\mathrm{DC}$ sputtering of $\mathrm{Zn}$ metallic target provide much more control of the films' oxygen content which is potential to tailor $\mathrm{ZnO}$ films properties, whereas RTA in nitrogen gas ambient helps to exclusively understand the influence of the oxygen content contained in these $\mathrm{Zn}$ metallic films under this controlled annealing processes.

\section{Materials and Methods}

Zinc thin films were DC sputtered on glass substrates by magnetron sputtering of high purity $(99.99 \%)$ Plasmaterials Inc. metallic disk (diameter $5.08 \mathrm{~cm}$ ) zinc target at room temperature in argon-oxygen gas environment followed by post-deposition RTA at different temperatures. The sputtering chamber was evacuated to a base pressure of $5.0 \times 10^{-6}$ mbar before films deposition. High purity argon gas (99.99\%) was allowed into the chamber at $50 \mathrm{ml} / \mathrm{min}$. Pre-sputtering was carried out for 5 minutes to remove contaminants from the surface of the target. Oxygen gas of high purity $(99.99 \%)$ was allowed into the chamber at $50 \mathrm{ml} / \mathrm{min}$. Films of $300 \mathrm{~nm}$ were deposited for 10 minutes on the substrates located about $15 \mathrm{~cm}$ from the target at a working pressure of $6.0 \times 10^{-3} \mathrm{mbar}$ and sputtering power of $175 \mathrm{~W}$. Temperature change on the surface of the substrate during sputtering was monitored using a thermocouple embedded on the substrate surface as shown in Figure 1.

The films were RTA at different temperatures in an evacuated rapid thermal processing (RTP) system chamber containing nitrogen gas. The as-deposited films were loaded into the RTP system chamber which was evacuated using the rotary pump for 30 minutes. Nitrogen gas (purity 99.99\%) was allowed into the chamber at $60 \mathrm{ml} / \mathrm{min}$ through a gas controller. The RTP was ramped up at 20 ${ }^{\circ} \mathrm{C} / \mathrm{sec}$ to the desired temperature. The films were annealed for 5 minutes at $100{ }^{\circ} \mathrm{C}, 150$, ${ }^{\circ} \mathrm{C}, \quad 200{ }^{\circ} \mathrm{C}, 250{ }^{\circ} \mathrm{C}$ and $300{ }^{\circ} \mathrm{C}$. After annealing the system were allowed to cool down naturally to room temperature. The annealed films were analysed for structural, morphological, optical, and electrical properties. Films' thicknesses were determined using the Alpha Step surface profiler. The films' surface morphology was determined using Scanning Electron Microscopy (SEM) operating at $2.0 \mathrm{kV}$. The films' grains distribution and surface roughness were analysed from the SEM images using Image $\mathbf{J}$ software (v1.53g60) (Rueden et al. 2017) and WSxM software (version 4.0) (Horcas et al. 2007), respectively. The structural properties were determined using an X-ray Diffractometer (XRD) using $0.1504 \mathrm{~nm}$ wavelength $\mathrm{Cu} \mathrm{K}$ alpha radiation. The reference data from the RUFF project database (Lafuente et al. 2015) were used to determine the phases of the films. The transmittance spectra $\left(T_{\text {sol }}\right)$ in the 
wavelength range 250-2500 $\mathrm{nm}$ were determined using UV/VIS/NIR spectrophotometer (Perkin Elmer Lambda 19). The electrical resistivity, and carrier concentrations and mobility were determined using the Hall Effect Measurement system (Ecopia HMS 3000).

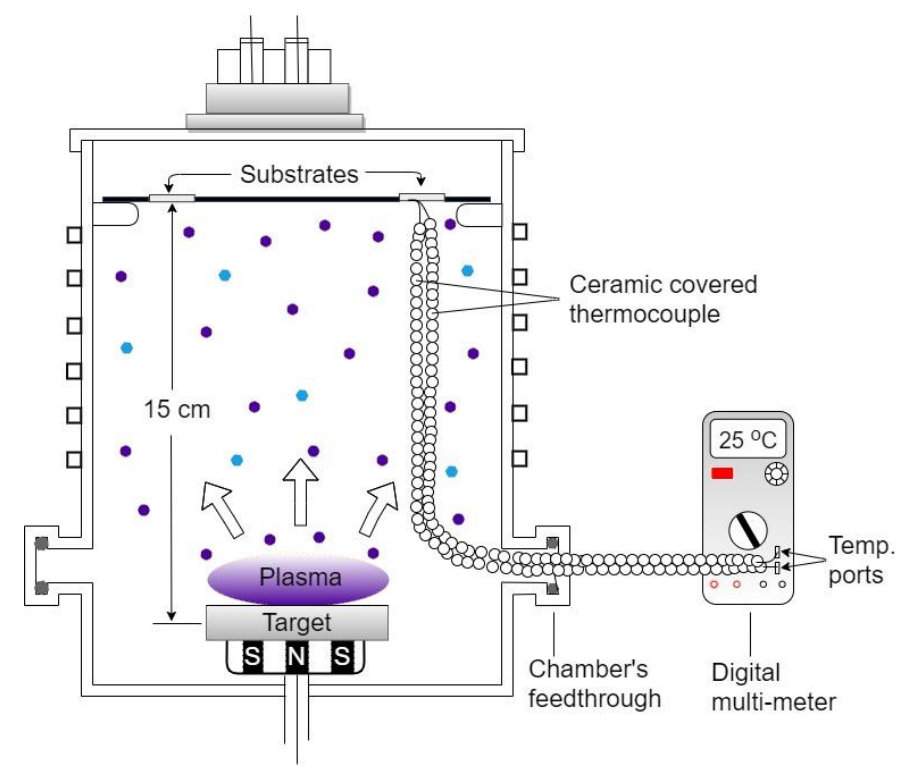

Figure 1: Schematic diagram of the sputtering chamber with a thermocouple connecting the substrate surface to the outside digital multi-meter through the chamber's feed-through.

\section{Results and Discussion XRD analysis}

The XRD patterns (Figure 2a) showed for the as-deposited films intermediate peaks between Zn (RRUFF ID: R070497) and ZnO (RRUFF ID: R050492) phases suggesting that mixed solid-phase of these materials form at room temperature. XRD studies on similar films sputtered at room temperature reported amorphous (Barker et al. 1997) or ZnO phase (Zhang et al. 2009). The mixed-phase observed in this work is likely driven by energy supplied by sputtered species (Georgieva et al. 2009) related to sputtering parameters. Films that were annealed at $100{ }^{\circ} \mathrm{C}$ revealed no structural change relative to the as-deposited films implying that this annealing temperature is still insufficient to form distinct $\mathrm{ZnO}$ phases. However, at an annealing temperature of 150 ${ }^{\circ} \mathrm{C}$ distinct $\mathrm{Zn}$ and $\mathrm{ZnO}$ peaks were observed. For temperatures above that, the peaks still existed with some variations above or below that at $150{ }^{\circ} \mathrm{C}$. Peaks observed at around $34.4^{\circ}$ were assigned to (002) planes of $\mathrm{ZnO}$ (RRUFF ID: R050492), while other peaks were assigned to $\mathrm{Zn}$ (RRUFF ID: R070497) and $\mathrm{SiO}_{2}$ (RRUFF ID: R060648). The co-existed $\mathrm{Zn}$ and $\mathrm{ZnO}$ phase can be ascribed to saturation of $\mathrm{ZnO}$ formation likely due to depleted oxygen contained in the as-deposited films. The silicon oxide phase observed likely originates from the glass substrate and have also been reported for room-temperature deposited $\mathrm{ZnO}$ (GarcíaGancedo et al. 2012). These findings suggest that the present deposition approach is potential for $\mathrm{ZnO}$ thin films phases and structural control that might be of interest for applications in optoelectronics (Reshchikov et al. 2007).

To assess the growth of the $\mathrm{ZnO}$ phases observed with annealing temperature, we computed the crystallite size related to (002) 
planes assigned to $\mathrm{ZnO}$ thin films using the Debye-Scherer formula

$$
D=0.94 \lambda / \beta \cos \theta
$$

where, $\mathrm{D}, \lambda, \theta$, and $\beta$ represent grain size, $\mathrm{XRD}$ radiation wavelength, Bragg angle, and Full-Width at Half Maximum, respectively. The analysis by this formula revealed a general increase in $\mathrm{ZnO}$ crystallite sizes with

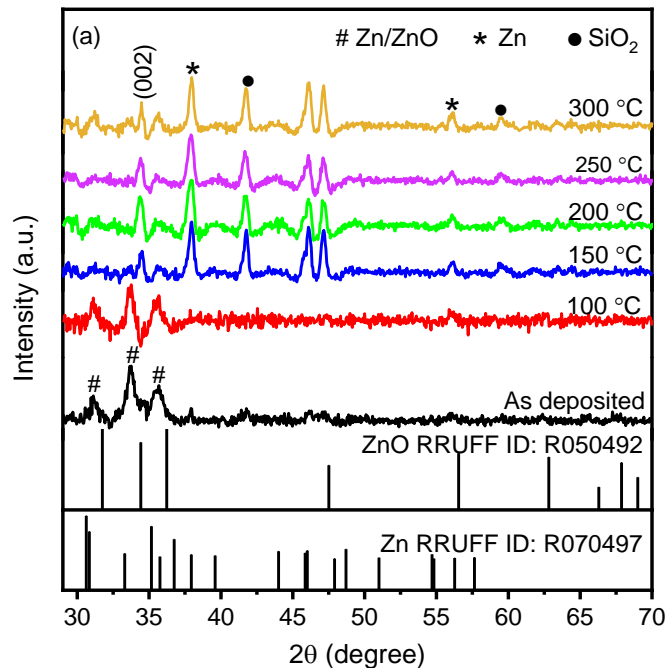

Figure 2: XRD pattern (a), and the crystallite size (b) for the as-deposited and annealed $\mathrm{ZnO}$ thin films.

\section{SEM analysis}

The SEM images (Figure 3a) showed evenly distributed large and small roundish clustered grains for the as-deposited films suggesting films' grain grows before annealing processing. Such growth of grains before annealing processing has been reported for $\mathrm{ZnO}$ thin films deposited at room temperature (Jang et al. 2010). This has been mostly ascribed to un-intentional substrate heating resulting from energetic atoms bombarding the surface of this substrate during films sputtering (Nennewitz et al. 1994). Increasing temperature due to these bombarding atoms is an unlikely cause of the films' grains observed here prior to annealing as the change in the substrate temperature during sputtering was negligibly small (from $25^{\circ} \mathrm{C}$ to $29^{\circ} \mathrm{C}$ ) to cause these films' observed grains growth. The small increasing annealing temperature (Figure 2b). The relative lower $\mathrm{ZnO}$ crystallite size for films that were annealed at $200{ }^{\circ} \mathrm{C}$ as compared to the rest of the films might be related to a release of adsorbed oxygen gas from the film's surface at this annealing temperature (Mahmood et al. 2010).

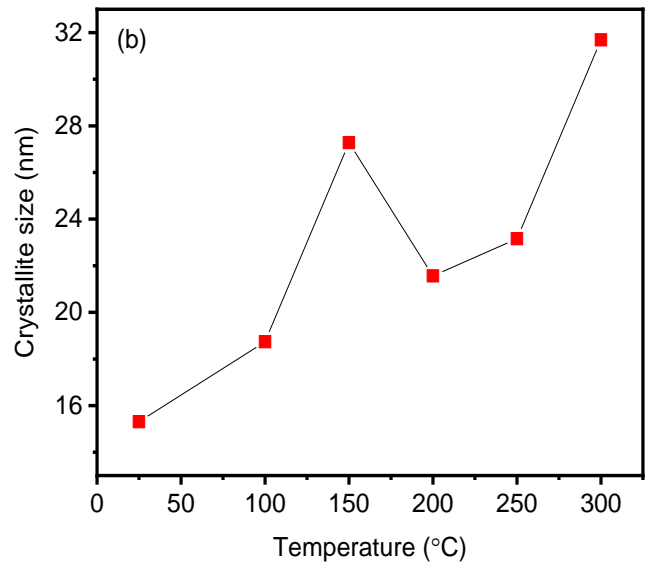

change in substrate temperature is likely due to the relatively large target to substrate distance and short sputtering time used in this work. The films' grains growth around room temperature can be explained by energy provided by the depositing species (Georgieva et al. 2009) rather than the elevated temperature of the substrate. Relative smaller and well-defined grains are observed for films that were annealed at $300{ }^{\circ} \mathrm{C}$ (Figure 3b) as compared to the as-deposited films (Figure 3a) suggesting an evolution of the films surface morphology with increasing annealing temperatures (Jang et al. 2010). Findings from this analysis suggest that annealing of films deposited using this approach is potential for these thin films surface morphology engineering. 

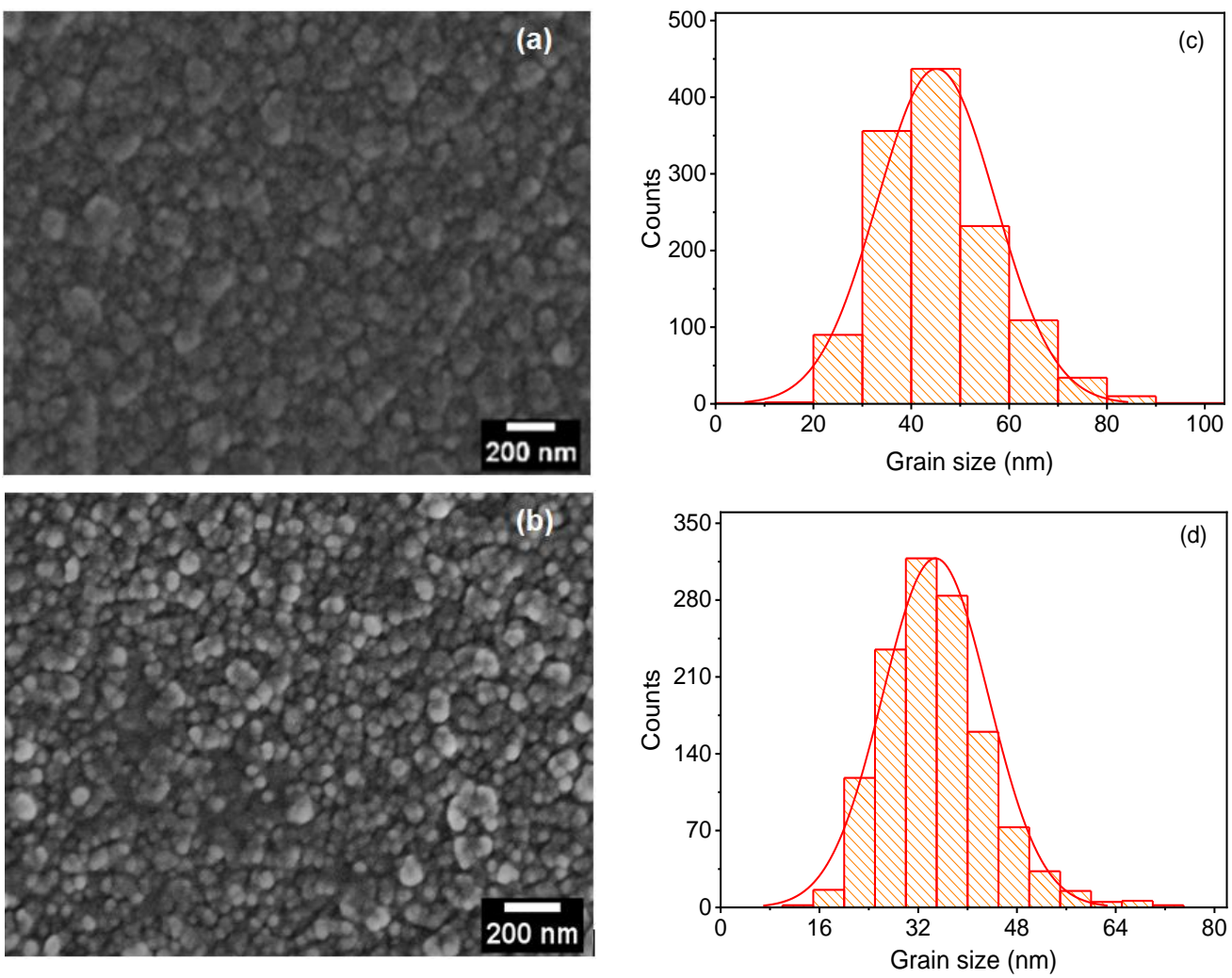

Figure 3: SEM images and grains distribution for as-deposited (a, c) and annealed at $300{ }^{\circ} \mathrm{C}(\mathrm{b}, \mathrm{c})$ $\mathrm{ZnO}$ thin films.

The analysis of the films' grains distribution revealed nearly normal distributed grains for both the as-deposited (Figure 3c) and films that were annealed at $300{ }^{\circ} \mathrm{C}$ (Figure 3d) with average grain sizes of $45.2 \mathrm{~nm}$ and 29.8 $\mathrm{nm}$, respectively (Table 1). This showed relative decrease in grains sizes which can be explained by an increase in films' crystallization with an increase in annealing temperature (Hong and Ro 2013). The larger grain size for the as-deposited films as compared to its crystallite size (Table 1) suggests that the estimated grain size included clustered grains unlike crystallite size determination which depended on localized $\mathrm{ZnO}$ phase crystallites. The grains get less clustered and become nearly spherical in shapes for the films that were annealed at 300 ${ }^{\circ} \mathrm{C}$ (Hezam et al. 2010). Therefore, achieving relatively similar grain sizes determined from SEM lateral surface scanning $(29.8 \mathrm{~nm})$ and the crystallite size determined from XRD vertical surface probing $(31.5 \mathrm{~nm})$. Relative higher surface roughness and root-mean-square roughness (RMS) were observed for films that were annealed at $300{ }^{\circ} \mathrm{C}$ as compared to the asdeposited films (Table 1). This suggested an increase in surface roughness with the films' oxide phase formation as annealing temperature increases (Daniel et al. 2010). These grains sizes and roughness parameters are within the reported values potential for optoelectronics applications (Malik et al. 2019). 
Ollotu et al. - Effects of rapid thermal annealing on the properties of room-temperature ...

Table 1: Crystallite size, grain size, and surface parameters for the as-deposited and annealed at $300{ }^{\circ} \mathrm{C} \mathrm{ZnO}$ thin films

\begin{tabular}{lcc}
\hline Parameter & As-deposited & RTA at $300{ }^{\circ} \mathrm{C}$ \\
\hline Crystallite size $(\mathrm{nm})$ & 15.4 & 31.5 \\
Grain size $(\mathrm{nm})$ & 45.2 & 29.8 \\
Surface roughness, $S_{\mathrm{a}}(\mathrm{nm})$ & 0.236 & 0.403 \\
RMS roughness, $S_{\mathrm{q}}(\mathrm{nm})$ & 0.732 & 0.829 \\
\hline
\end{tabular}

\section{Transmittance properties}

Figure 4(a) shows solar transmittance $\left(T_{\text {sol }}\right)$ spectra that are relatively lower and of different shapes for the samples as compared to that of bare glass substrate an indication that samples of different optical properties were deposited on the bare glass. The area under $T_{\text {sol }}$ spectra increased for annealed films as compared to the as-deposited films implying a relative improved $T_{\text {sol }}$ due to improved phase content and crystallization (Eneku et al. 2018, Malik et al. 2019) with increasing annealing temperature evident in our XRD data. A relatively large difference in the areas under $T_{\text {sol }}$ spectra is observed between the as-deposited, films annealed at $100{ }^{\circ} \mathrm{C}$ and $150{ }^{\circ} \mathrm{C}$ as compared to that between films annealed at $200{ }^{\circ} \mathrm{C}, 250{ }^{\circ} \mathrm{C}$ and $300{ }^{\circ} \mathrm{C}$ with a relatively similar area under $T_{\text {sol }}$ spectra. The former suggests that the films are undergoing significant phase and crystallinity evolution resulting in varied $T_{\text {sol }}$, while the later signify stable $\mathrm{ZnO}$ phase and crystallinity with high and nearly similar $T_{\text {sol }}$. Films that were annealed at $250{ }^{\circ} \mathrm{C}$ and $300{ }^{\circ} \mathrm{C}$ have $T_{\text {sol }}$ very close to that of bare glass around the verge of visible-infrared region suggesting that these films show anti-reflection properties (Granqvist 2007).

The films' average solar transmittance, $T_{\mathrm{AVE}}$ was computed based on Equation (2) (Maghanga et al. 2010) using Air Mass 1.5 solar irradiance, $G(\lambda)$ in the range $250-2500$ nm.

$$
T_{\mathrm{AVE}}=\sum_{250}^{2500} T(\lambda) G(\lambda) / \sum_{250}^{2500} G(\lambda)
$$

The computed average transmittance $\left(T_{\mathrm{AVE}}\right)$ as a function of annealing temperature (Figure 4b) shows a relative low $T_{\mathrm{AVE}}$ value for asdeposited as compared to the plain glass substrate and a general increase of this average with increasing annealing temperature as compared to the as-deposited films. This agrees well with the trend observed for these films $T_{\text {sol }}$ spectra (Figure 4a). Films that were annealed at $200{ }^{\circ} \mathrm{C}$ and above showed relative high similar values of $T_{\mathrm{AVE}}$ at about $80 \%$ which is reportedly suitable for applications in thin film solar cells window layer (Khan et al. 2017). 

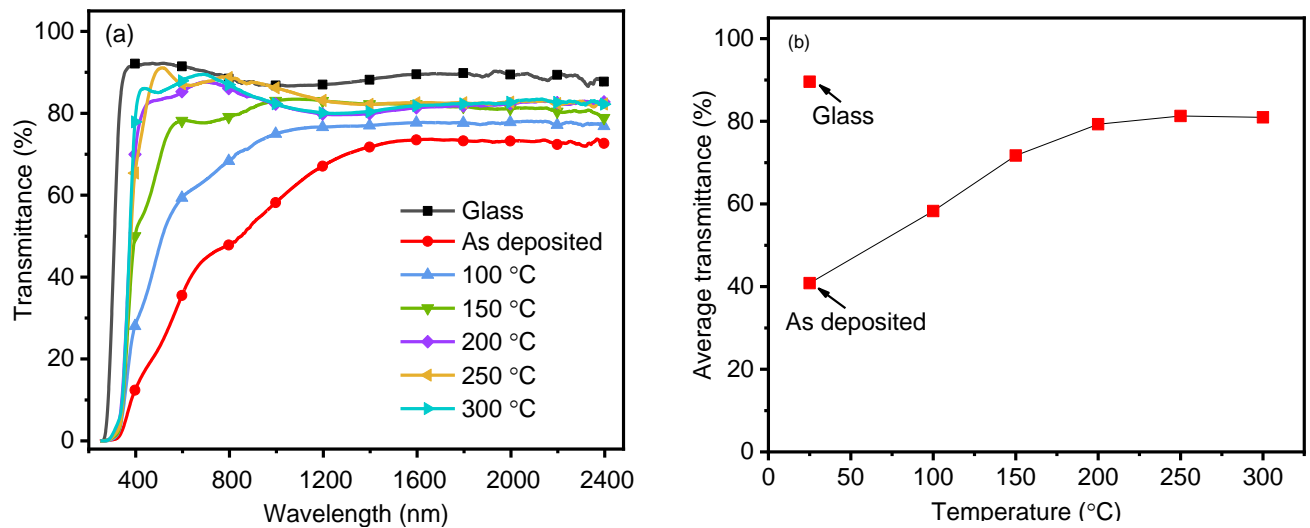

Figure 4: $\quad$ Solar transmittance spectra, $T_{\mathrm{sol}}(\mathrm{a})$, and average transmittance $\left(T_{\mathrm{AVE}}\right)$ (b) as a function of annealing temperature for as-deposited and annealed $\mathrm{ZnO}$ thin films.

\section{Bandgap properties}

The films' bandgap energy $E_{\mathrm{g}}$ was estimated from the films' absorption coefficient $\alpha$ computed from the solar transmittance spectra $T(\lambda)$ which relate as (Song et al. 2011)

$$
T(\lambda)=A \exp (\alpha t)
$$

Besides, for $\mathrm{ZnO}$ thin films with a direct interband transition, the bandgap and $\alpha$ relate as

$$
(\alpha h v)^{2}=\beta\left(h v-E_{\mathrm{g}}\right)
$$

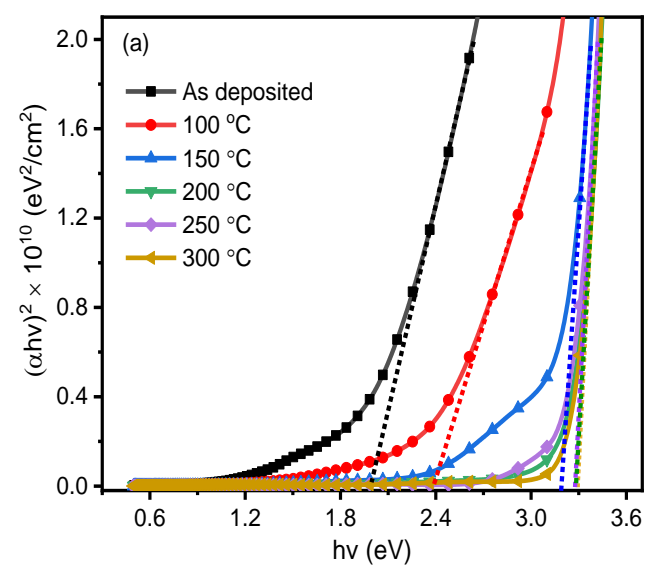

where $A$ and $\beta$ are constants and $t$ is the films' thicknesses. The bandgaps were estimated by plotting $(\alpha h v)^{2}$ against photon energy $h v$ and extrapolating a linear part of the plot toward $(\alpha h v)^{2}=0$. The extrapolated plots (Figure 5a) and the estimated energy bandgaps (Figure 5b) revealed a relatively larger bandgap for the annealed films as compared to the asdeposited films. This relative high bandgap is also suggested by the $T_{\text {sol }}$ spectra absorption edge blue-shift for these films with increased annealing temperature (Malik et al. 2019).

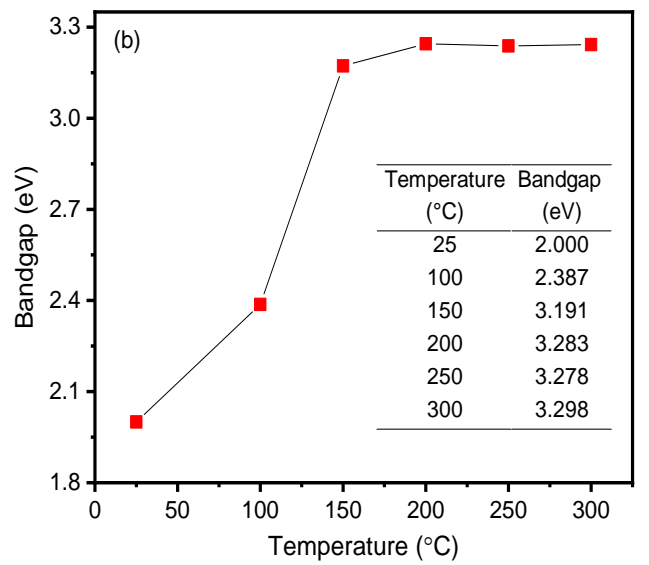

Figure 5: Tauc plots and extrapolations (a) and estimated bandgap (b) for as-deposited and annealed $\mathrm{ZnO}$ thin films. 
Ollotu et al. - Effects of rapid thermal annealing on the properties of room-temperature ...

The bandgap increased with increasing annealing temperature up to $200{ }^{\circ} \mathrm{C}$, thereafter recording a relative similar value beyond this temperature. This finding agrees well with the observed $T_{\text {sol }}$ spectra properties of these films and can be explained by the similar evolution of microstructure pointed out earlier in the structure analysis. This increase in bandgap is reported to be important for optoelectronic applications (Malik et al. 2019). A relative small variation in the bandgaps for films annealed at $200{ }^{\circ} \mathrm{C}$ and beyond is likely due to slightly varied films' microstructure defects and carrier concentrations due to decreased oxygen vacancies with these films annealing temperatures (Dhara and Giri 2011). The bandgap for the best films in the present study is close (the highest achieved is $3.30 \mathrm{eV}$ ) to the reported bandgap of $\mathrm{ZnO}$ thin films $(3.37 \mathrm{eV})$ (Ghosh et al. 2015). These findings suggest that the fabrication approach in this work is potential to achieve $\mathrm{ZnO}$ with bandgap potential for application in CZTS solar cells window layer.

\section{Electrical properties}

The Hall Effect measurement showed rather similar carrier concentration values for the asdeposited and films that were annealed at 100 ${ }^{\circ} \mathrm{C}$ (Figure 6a). However, films annealed at 150 ${ }^{\circ} \mathrm{C}$ and $200{ }^{\circ} \mathrm{C}$ had relative higher carrier concentrations as compared to the rest of the films. This finding suggests that carriers in the former two films are trapped by stilldeveloping films grains within these films. Relative higher values of carrier concentrations for films that were annealed at $150{ }^{\circ} \mathrm{C}$ and 200 ${ }^{\circ} \mathrm{C}$ suggest relative reduced grains carrier trapping with increasing annealing temperature. Further increase in annealing temperature beyond $200{ }^{\circ} \mathrm{C}$ revealed a decrease in carrier concentrations likely due to reduced oxygen vacancies responsible for carriers in $\mathrm{ZnO}$ films (Ghosh et al. 2015). These films also showed high carrier mobility (Figure 6b) which is likely due to improved crystallinity and reduced carrier-carrier scattering related to these films reduced carrier concentrations (McLean and Paige 1960). Besides, relatively low carrier mobility recorded for the films that were annealed at $150{ }^{\circ} \mathrm{C}$ and $200{ }^{\circ} \mathrm{C}$ can be explained by increased carrier-carrier scattering due to the increased carrier concentrations in these films. Whereas relative lower carrier mobility for the as-deposited and annealed at $100{ }^{\circ} \mathrm{C}$ suggest scattering of the carrier on the still-developing grains at these conditions. The Hall measurement also showed that with increasing annealing temperature, the films' electrical resistivity decreased exponentially (Figure 6c). This decrease can be explained by the combined effects of these films' carriers' concentrations and mobility related to these films microstructures. 

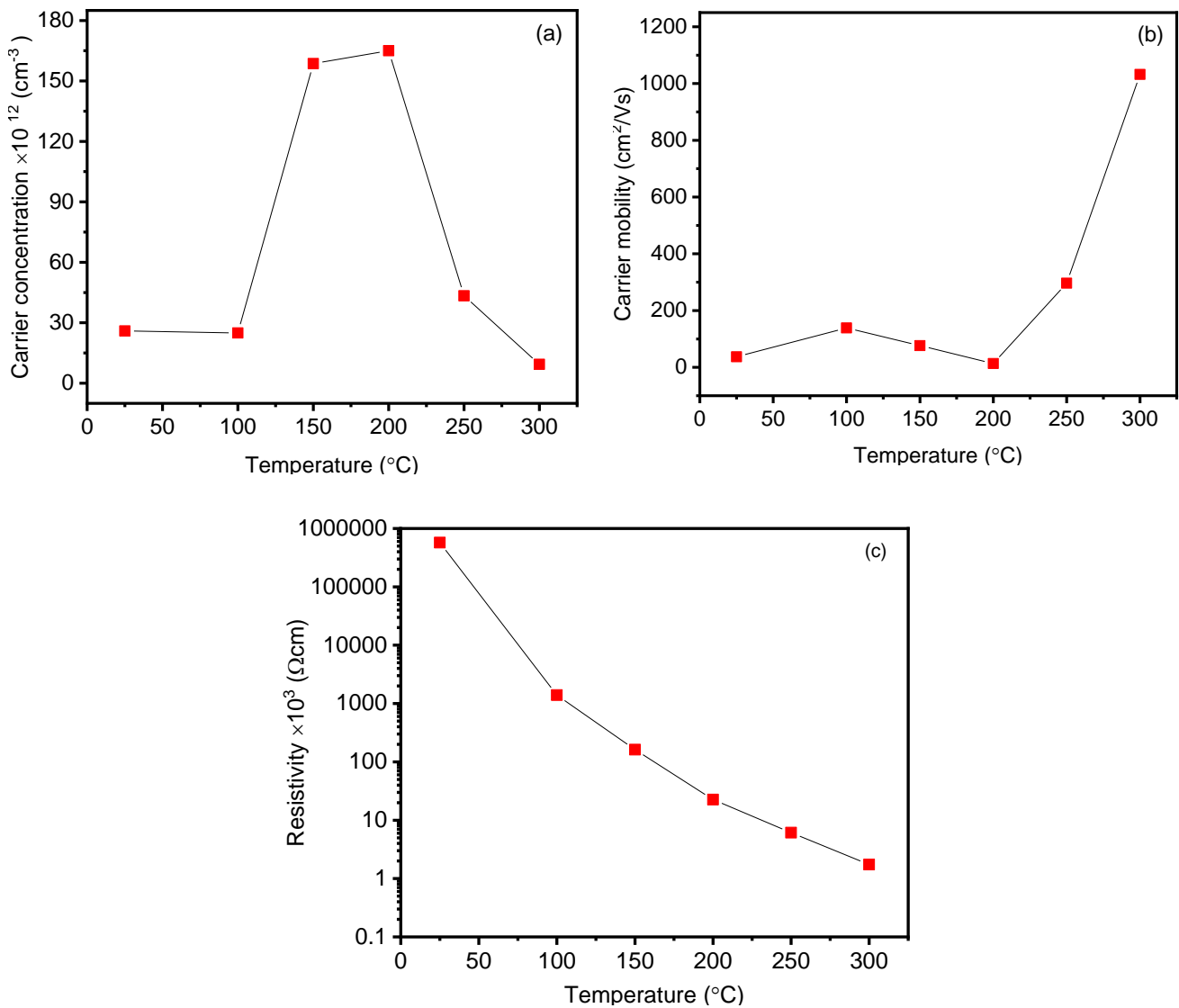

Figure 6: Carrier concentrations (a), carrier mobility (b), and resistivity (c) for as-deposited and annealed $\mathrm{ZnO}$ thin films.

\section{Conclusion}

In this work we found that, potential $\mathrm{ZnO}$ thin films desired for CZTS solar cells window layer applications can be achieved by RTA of room-temperature oxygenated DC sputtered $\mathrm{Zn}$ thin films carried out under nitrogen gas environment. The observed desired properties as window layer applications include the relative high films grains, optical bandgap and average solar transmittance. $\mathrm{ZnO}$ phase was also observed for films RTA at $150{ }^{\circ} \mathrm{C}$ and above with an impact on the electrical properties of the films indicating a potential to grow $\mathrm{ZnO}$ thin films purity phases at these annealing temperatures upon further sputtering parameter optimization. The best films had a high $T_{\mathrm{AVE}}$ of about $80 \%, E_{\mathrm{g}}$ of $3.30 \mathrm{eV}$ and electrical resistivity of $1.74 \times 10^{3} \Omega \mathrm{cm}$ achieved at an annealing temperature of 300 ${ }^{\circ} \mathrm{C}$. The present deposition approach extends the possibility to achieve $\mathrm{ZnO}$ thin films for the CZTS thin films solar cells window layer.

\section{Conflict of Interest}

There is no conflict of interest to declare.

\section{Acknowledgement}

The authors wish to acknowledge the International Science Program (ISP)-Uppsala University and the University of Dar es Salaam for laboratory supports, and Mkwawa University College of Education for the $\mathrm{PhD}$ scholarship. 
Ollotu et al. - Effects of rapid thermal annealing on the properties of room-temperature ...

\section{References}

Barker A, Crowther S and Rees D 1997 Roomtemperature rf magnetron sputtered $\mathrm{ZnO}$ for electromechanical devices. Sensors Actuators, A Phys. 58 (3): 229-235.

Daniel GP, Justinvictor VB, Nair PB, Joy K, Koshy P and Thomas PV 2010 Effect of annealing temperature on the structural and optical properties of $\mathrm{ZnO}$ thin films prepared by RF magnetron sputtering. Phys. $B$ Condens. Matter 405 (7): 1782-1786.

Dhara S and Giri PK 2011 Enhanced UV photosensitivity from rapid thermal annealed vertically aligned $\mathrm{ZnO}$ nanowires. Nanoscale Res. Lett. 6(1): 504.

Eneku JP, Otiti T, Mwabora JM and Horwat D 2018 Effects of substrate radial-position relative to the sputter-gun axis on the electrical, optical and structural properties of $\mathrm{ZnO}$ thin films deposited by reactive direct current magnetron sputtering. Tanz. J. Sci. 44(4): 12-20.

García-Gancedo L, Pedrós J, Zhu Z, Flewitt AJ, Milne WI, Luo JK and Ford CJB 2012 Room-temperature remote-plasma sputtering of c-axis oriented zinc oxide thin films. J. Appl. Phys. 112(1): 014907.

Georgieva V, Saraiva M, Jehanathan N, Lebelev OI, Depla D and Bogaerts A 2009 Sputter-deposited $\mathrm{Mg}-\mathrm{Al}-\mathrm{O}$ thin films: linking molecular dynamics simulations to experiments. J. Phys. D. Appl. Phys. 42(6): 065107.

Ghosh SP, Das KC, Tripathy N, Bose G, Kim DH, Lee TI, Myoung JM and Kar JP 2015 Microstructural evolution of sputtered $\mathrm{ZnO}$ thin films with rapid thermal annealing. $J$. Mater. Sci. Mater. Electron. 26(10): 78607866.

Granqvist CG 2007 Transparent conductors as solar energy materials: A panoramic review. Sol. Energy Mater. Sol. Cells 91(17): 1529-1598.

Hezam M, Tabet N and Mekki A 2010 Synthesis and characterization of DC magnetron sputtered $\mathrm{ZnO}$ thin films under high working pressures. Thin Solid Films 518 (24): e161-e164.
Hong WE and Ro JS 2013 Kinetics of solid phase crystallization of amorphous silicon analyzed by Raman spectroscopy. J. Appl. Phys. 114(7): 073511.

Horcas I, Fernández R, Gómez-Rodríguez JM, Colchero J, Gómez-Herrero J and Baro AM 2007 WSXM: A software for scanning probe microscopy and a tool for nanotechnology. Rev. Sci. Instrum. 78(1): 013705.

Hsieh PT, Chen YC, Wang CM, Tsai YZ and $\mathrm{Hu} \quad \mathrm{CC} 2006$ Structural and photoluminescence characteristics of $\mathrm{ZnO}$ films by room temperature sputtering and rapid thermal annealing process. Appl. Phys. A 84(3): 345-349.

Husna J, Aliyu MM, Islam MA, Chelvanathan P, Hamzah NR, Hossain MS, Karim MR and Amin N 2012 Influence of annealing temperature on the properties of $\mathrm{ZnO}$ thin films grown by sputtering. Energy Procedia 25: 55-61.

Jang YR, Yoo K-H and Park SM 2010 Rapid thermal annealing of $\mathrm{ZnO}$ thin films grown at room temperature. J. Vac. Sci. Technol. A 28(2): 216-219.

Khan MI, Bhatti KA, Qindeel R, Alonizan N and Althobaiti HS 2017 Characterizations of multilayer $\mathrm{ZnO}$ thin films deposited by sol-gel spin coating technique. Results Phys. 7: 651-655.

Lafuente B, Downs RT, Yang H and Stone N 2015 The power of databases: The RRUFF project. In: Armbruster T and Danisi RMD (Eds) Highlights in Mineralogical Crystallography (pp. 1-29), Degruyter, Switzerland.

Maghanga CM, Jensen J, Niklasson GA, Granqvist CG and Mwamburi M 2010 Transparent and conducting $\mathrm{TiO}_{2}: \mathrm{Nb}$ films made by sputter deposition: Application to spectrally selective solar reflectors. Sol. Energy Mater. Sol. Cells 94(1): 75-79.

Mahmood A, Ahmed N, Raza Q, Khan TM, Mehmood M, Hassan MM and Mahmood N 2010 Effect of thermal annealing on the structural and optical properties of $\mathrm{ZnO}$ thin films deposited by the reactive e-beam 
evaporation technique. Phys. Scr. 82(6): 065801.

Malik G, Mourya S, Jaiswal J and Chandra R 2019 Effect of annealing parameters on optoelectronic properties of highly ordered $\mathrm{ZnO}$ thin films. Mater. Sci. Semicond. Process. 100: 200-213.

McLean TP and Paige EGS 1960 A theory of the effects of carrier-carrier scattering on mobility in semiconductors. J. Phys. Chem. Solids 16(3): 220-236.

Nennewitz O, Schmidt H, Pezoldt J, Stauden T, Schawohl J and Spiess L 1994 Rapid thermal annealing of thin $\mathrm{ZnO}$ films. Phys. Stat. Sol. 145(2): 283-288.

Ozgur Ü, Hofstetter D and Morkoç H 2010 $\mathrm{ZnO}$ devices and applications: A review of current status and future prospects. Proc. IEEE 98(7): 1255-1268.

Pal K, Singh P, Bhaduri A and Thapa KB 2019 Current challenges and future prospects for a highly efficient $(>20 \%)$ kesterite CZTS solar cell: A review. Sol. Energy Mater. Sol. Cells 196: 138-156.

Pholds L, Samiji ME, Mlyuka NR, Richards BS and Kivaisi RT 2013 Boron doped zinc oxide films grown by DC reactive magnetron sputtering. In: $28^{\text {th }}$ European Photovoltaic Solar Energy Conference and Exhibition (28 ${ }^{\text {th }}$ EU PVSEC) (pp. 231152315), Paris, France.
Reshchikov MA, Morkoç H, Nemeth B, Nause J, Xie J, Hertog B and Osinsky A 2007 Luminescence properties of defects in $\mathrm{ZnO}$. Phys. B Condens. Matter 401-402: 358361.

Rueden CT, Schindelin J, Hiner MC, DeZonia BE, Walter AE, Arena ET and Eliceiri KW 2017 ImageJ2: ImageJ for the next generation of scientific image data. $B M C$ Bioinformatics 18(1): 1-26.

Ryu SY, Seo JH, Hafeez H, Song M, Shin JY, Kim DH, Jung YC and Kim CS 2017 Effects of the wrinkle structure and flat structure formed during static lowtemperature annealing of $\mathrm{ZnO}$ on the performance of inverted polymer solar cells. J. Phys. Chem. C 121(17): 91919201.

Samwel B, Samiji ME and Mlyuka NR 2015 Effects of target composition on the optical constants of DC sputtered $\mathrm{ZnO}$ : Al thin films. Tanz. J. Sci. 41(1): 38-47.

Song S, Yang T, Liu J, Xin Y, Li Y and Han S 2011 Rapid thermal annealing of ITO films. Appl. Surf. Sci. 257(16): 7061-7064.

Zhang D, Fan P, Cai X, Huang J, Ru L, Zheng Z, Liang G and Huang Y 2009 Properties of $\mathrm{ZnO}$ thin films deposited by $\mathrm{DC}$ reactive magnetron sputtering under different plasma power. Appl. Phys. A 97(2): 437441 . 